archives-ouvertes

\title{
Botulinum Toxin Injection and Airflow Stability in Spasmodic Dysphonia
}

Giovanna Cantarella, Alessandra Berlusconi, Barbara Maraschi, Alain Ghio, Sergio Barbieri

\section{To cite this version:}

Giovanna Cantarella, Alessandra Berlusconi, Barbara Maraschi, Alain Ghio, Sergio Barbieri. Botulinum Toxin Injection and Airflow Stability in Spasmodic Dysphonia. Otolaryngology Head and Neck Surgery, SAGE Publications (UK and US), 2006, 134 (3), pp.419 - 423. $<10.1016 /$ j.otohns.2005.10.028> $>$ <hal-01616014>

\section{HAL Id: hal-01616014 https://hal.archives-ouvertes.fr/hal-01616014}

Submitted on 20 Apr 2018

HAL is a multi-disciplinary open access archive for the deposit and dissemination of scientific research documents, whether they are published or not. The documents may come from teaching and research institutions in France or abroad, or from public or private research centers.
L'archive ouverte pluridisciplinaire HAL, est destinée au dépôt et à la diffusion de documents scientifiques de niveau recherche, publiés ou non, émanant des établissements d'enseignement et de recherche français ou étrangers, des laboratoires publics ou privés. 


\title{
Botulinum Toxin Injection and Airflow Stability in Spasmodic Dysphonia
}

\author{
Giovanna Cantarella, MD, Alessandra Berlusconi, MD, \\ Barbara Maraschi, BSc, Alain Ghio, PhD, and Sergio Barbieri, MD, \\ Milan, Italy
}

\begin{abstract}
OBJECTIVE: The aim of this study was to analyze the effects of botulinum toxin (BT) injection on airflow stability, by measuring mean phonatory oral airflow and its coefficient of variation (CV), in subjects with adductor spasmodic dysphonia (SD).

STUDY DESIGN AND SETTING: Twenty-four subjects with SD (aged 31-78 years) and 23 controls (aged 29-63 years) were evaluated for mean airflow and its CV during sustained phonation. Fifteen of the subjects with SD were also evaluated within 3 weeks after BT injection.

RESULTS: BT increased airflow in subjects $(P=0.0130)$ but neither the preinjection nor postinjection values differed significantly from those of controls. Conversely, airflow CV was invariably higher in subjects than in controls $(P<0.0001)$. In 13 subjects in whom phonation perceptually improved, including 3 in whom airflow did not increase, airflow CV decreased significantly after BT treatment $(P=0.0232)$.
\end{abstract}

CONCLUSIONS: Subjects with SD have highly unstable phonatory airflow; its $\mathrm{CV}$ is a valid measure for assessing the outcome of a BT injection. A reduced airflow CV probably does not depend solely on increased airflow due to thyroarytenoid muscle paresis, and may indicate a change in laryngeal motoneuronal activity.

EBM rating: $\mathbf{B}-\mathbf{3 b}$

(C) 2006 American Academy of Otolaryngology-Head and Neck Surgery Foundation, Inc. All rights reserved.

$\mathbf{S}^{\mathrm{p}}$ pasmodic dysphonia (SD) is a disabling motor disorder affecting the voice. Whereas in the past it was diagnosed and treated as a psychiatric disorder, it is currently considered to be a focal dystonia affecting the intrinsic laryngeal muscles. Among the various types described are adductor, abductor, mixed SD and SD with tremor. ${ }^{1-4}$ Although subjects with SD have a typically strained and strangled voice the grade of voice impairment varies greatly depending on the muscles involved by spasms, the severity of muscle hyperactivity, and the compensatory mechanisms during speech. The resulting speech characteristics are therefore influenced by several mechanisms and SD is described as a heterogeneous disorder., ${ }^{3,5}$

Whether SD is a single disease or it may arise from various pathophysiologic conditions is unclear. Previous investigations have shown that botulinum toxin (BT) injection into the thyroarytenoid (TA) muscles is the most effective symptomatic treatment for adductor $\mathrm{SD},{ }^{6}$ as it is for other types of focal dystonia. BT acts peripherally by inhibiting acetylcholine (Ach) release from the presynaptic nerve terminals thereby causing a flaccid paralysis of the injected muscle.

Only a few studies have analyzed the aerodynamic features of phonation in subjects with SD and described changes after BT treatment of the vocal muscles. ${ }^{7-11}$ Although subjects with SD would be expected to have a low translaryngeal airflow owing to overclosure of the vocal folds, ${ }^{9,10,12}$ some investigators report mean airflow within normal limits. ${ }^{7,13}$

Because BT acts by paralyzing the TA muscles, BT injections usually increase airflow. ${ }^{7-11}$ A limited number of studies have analyzed the variations in airflow during pho-

yngology-Head and Neck Surgery, New York, NY, September 19-22, 2004.

Reprint requests: Giovanna Cantarella, MD, Department of Otolaryngology, Fondazione Ospedale Maggiore Policlinico, Mangiagalli e Regina Elena, IRCCS, Pad. Alfieri, Via Commenda 1020122 Milano, Italy.

E-mail address: giovanna.cantarella@policlinico.mi.it 
nation by evaluating its stability over time in subjects with $\mathrm{SD}$ and assessing changes induced by BT treatment. ${ }^{7,8,12}$

In this study we investigated whether aerodynamic evaluation of voice production is useful in the diagnostic assessment and follow-up of subjects with SD undergoing BT treatment. To evaluate airflow stability over time, we measured mean oral airflow and its coefficient of variation (CV) during sustained phonation in subjects with adductor SD and in a group of control subjects and analyzed changes in both aerodynamic measures in subjects after BT treatment.

\section{MATERIAL AND METHODS}

\section{Subjects}

We studied 24 subjects (19 women, 5 men; aged 31-78 years, mean age $=54.7$ ) with adductor SD. Severity ranged from mild impairment of fluency to unintelligible speech in the most severe cases. The diagnosis was made by a neurolaryngological team comprising a laryngologist, a speech therapist and a neurologist, and mainly based on the presence of a strained, strangled quality of voice with phonatory breaks and on the subject's clinical history. Flexible video laryngoscopy confirmed over adduction and spasms of the vocal folds coinciding with the voice stops.

As a control group we enrolled 23 normal subjects (13 women, 10 men; aged 29-63 years, mean age $=53.4$ ) with no history of voice disorders. The protocol was approved by the hospital ethics committee and all participants gave their informed consent to the study.

\section{Botulinum Toxin Treatment}

All of the subjects received a percutaneous injection of BT type A (Botox) in both TA muscles under electromyographic guidance. Of the 24 subjects treated, 18 were receiving their first BT treatment, and 6 were being retreated. Botulinum toxin was injected at a dose of 2.5 mouse units per side in 15 subjects and the dose ranged from 0.675 to $5 \mathrm{U}$ per side in the remaining 9 subjects, depending on the severity of symptoms or the previous response to treatment, or both. Botulinum toxin was injected at a concentration of $2.5 \mathrm{U} / 0.1 \mathrm{ml}(1.25 \mathrm{U} / 0.1 \mathrm{ml}$ in subjects receiving $<2.5 \mathrm{U}$ per TA muscle).

\section{Aerodynamic Recordings}

The mean airflow was recorded while subjects and controls produced a sustained /a/ at comfortable pitch and intensity for at least $3 \mathrm{sec}$, and was measured with EVA2 workstation (SQ-Lab, Aix-en-Provence, France). A mouthpiece was placed on the subject's face, and held tightly around the mouth, to avoid air leaks. The mouthpiece was equipped with built-in acoustic and aerodynamic sensors that were coaxially arranged, to allow simultaneous recordings of acoustic and aerodynamic variables.

Airflow was measured with a constant-temperature mesh pneumotachograph. Voice data were displayed on the computer screen as four superposed curves corresponding to the sound wave, fundamental frequency in $\mathrm{Hz}$, sound pressure level (SPL) intensity in $\mathrm{dB}$, and airflow in $\mathrm{dm}^{3} / \mathrm{sec}$. A 1 -sec segment was then selected for analysis in the steadiest part of the tracings. The EVA2 software was used to compute the acoustic and aerodynamic data. Acoustic results are not considered in this paper. Airflow values were measured in $\mathrm{dm}^{3} / \mathrm{sec}$ and converted to $\mathrm{cc} / \mathrm{sec}$.

The CV of airflow, expressed as a percentage, was calculated by dividing the SD of airflow by the mean airflow:

$$
\mathrm{CV}=100 \times \frac{\text { airflow sd }}{\text { mean airflow }}
$$

The CV therefore expresses the middle term instability of airflow and can be seen as the scope in \% of airflow around its average value. Aerodynamic indexes were assessed before treatment in all subjects and in 15 subjects the recording was repeated within 3 weeks (range $=8$-20 days, mean $=14.4$ ) after treatment, when the voice improvement had stabilized and breathiness had subsided.

\section{Statistical Analysis}

All analyses were carried out using the GraphPad Prism statistical program. All values are expressed as means \pm standard deviation (SD). The Mann-Whitney test for independent variables was used to compare the mean airflow and the CV values in subjects and control subjects. Student's $t$-test for paired data was used to compare mean airflow and CV values before and after BT treatment in the 13 subjects achieving voice improvement. A $P$ value of $<0.05$ was considered statistically significant.

\section{RESULTS}

\section{Aerodynamic Results in Subjects With SD Versus Normal Subjects}

No significant difference was found in mean preinjection airflow values recorded in the 24 subjects and 23 controls $(P$ $=0.0928)$ (Fig 1). In both groups mean airflow showed a high degree of variability although 4 subjects (only 1 control) had airflow values below $50 \mathrm{cc} / \mathrm{sec}$. Two subjects exhibited values over $300 \mathrm{cc} / \mathrm{sec}(383 \mathrm{and} 671 \mathrm{cc} / \mathrm{sec})$. The airflow values ranged from 24 to $671 \mathrm{cc} / \mathrm{sec}$ in the SD subjects $($ mean $=145.2 \pm 138.0 \mathrm{cc} / \mathrm{sec})$ and from 46 to 259 $\mathrm{cc} / \mathrm{sec}$ in the controls $($ mean $=156.0 \pm 57.5 \mathrm{cc} / \mathrm{sec})$. Conversely, mean $\mathrm{CV}$ of airflow values were significantly higher in subjects than in controls $(P<0.0001): 64.8 \pm$ $88.3 \%($ range $=5.4 \%$ to $329.1 \%)$ vs $3.7 \pm 2.1 \%($ range $=$ $1.2 \%$ to $8.0 \%$ ) (Fig 2).

\section{Aerodynamic Evaluation After BT Treatment}

Aerodynamic recordings were repeated within 3 weeks after treatment in 15 of 24 subjects receiving BT injection in the TA muscles. The remaining 9 subjects were followed up only by telephone because they lived far away from our laboratory. Only 13 of 15 subjects who underwent post BT 


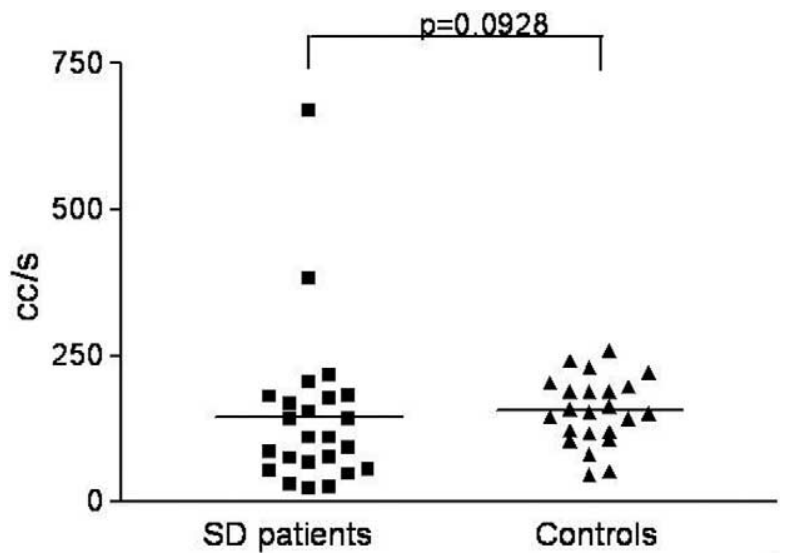

Figure 1 Values of phonatory oral airflow in the 24 subjects with adductor spasmodic dysphonia and 23 normal subjects. Note the wide dispersion of data in both groups. No significant difference was found between the 2 groups.

treatment recordings had a subjective and acoustic improvement in voice quality and fluency. In the 2 unimproved subjects postinjection airflow and $\mathrm{CV}$ of airflow values were similar to those obtained before treatment.

In the 13 subjects who benefitted from BT treatment, mean preinjection and postinjection airflow values differed significantly $(P=0.0130)$, the mean preinjection value being $106.5 \pm 61.9 \mathrm{cc} / \mathrm{sec}($ range $=26-205 \mathrm{cc} / \mathrm{sec})$ vs 237.2 $\pm 138.8 \mathrm{cc} / \mathrm{sec}($ range $=78-581 \mathrm{cc} / \mathrm{s})($ Fig 3$)$. In 10 of 13 subjects airflow increased, it remained unchanged in 2, and in the remaining female subject it significantly diminished (preinjection $182 \mathrm{cc} / \mathrm{sec}$ vs postinjection $78 \mathrm{cc} / \mathrm{sec}$ ). The difference between postinjection airflow values in subjects and controls was borderline but did not reach significance $(P=0.0652)$.

In 12 of 13 subjects in whom BT treatment improved phonation, including 1 subject in whom airflow also de-

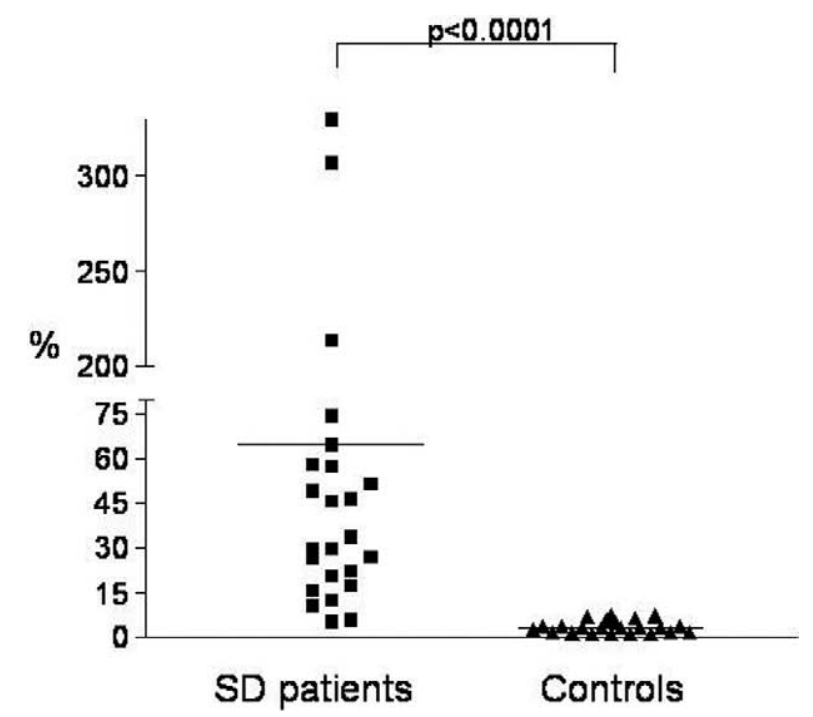

Figure 2 Coefficients of variation of airflow in subjects with spasmodic dysphonia and controls. Subjects values are significantly higher than those of controls.

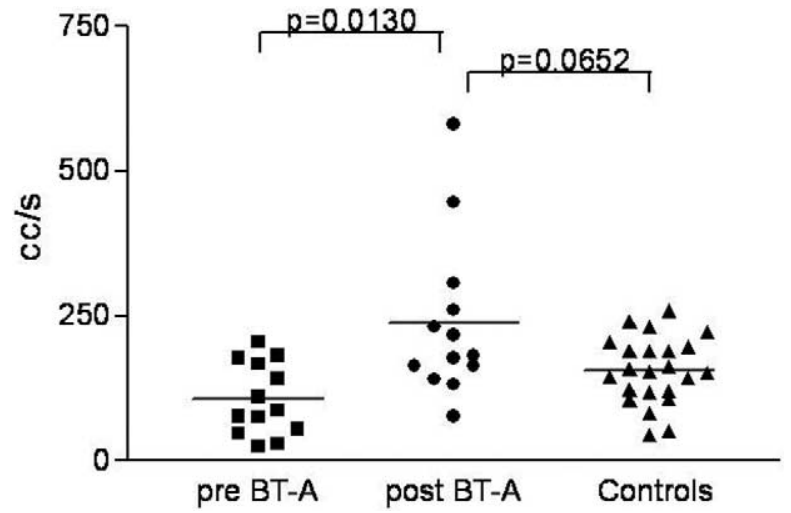

Figure 3 Graph showing pre- and post-BT treatment mean oral airflow (airflow) measured in 13 subjects with spasmodic dysphonia and in the 23 controls. Although post-treatment values are significantly higher than the pre-treatment values, they do not significantly differ from those of controls.

creased, the mean $\mathrm{CV}$ of airflow diminished (preinjection: $48.9 \pm 52.8 \%$, range $=12.7 \%$ to $213.5 \%$ vs postinjection: $9.9 \pm 7.5 \%$, range $=1.6 \%$ to $27.7 \%$ ). The decrease was statistically significant $(P=0.0232)$ (Fig 4$)$. The $\mathrm{CV}$ values were still significantly higher in treated subjects than in controls $(P=0.0006)$. In the subject in whom airflow decreased after BT treatment, $\mathrm{CV}$ diminished from $33.7 \%$ to $13.2 \%$.

Figure 5 reports an example of preinjection and postinjection airflow tracings in one of the subjects whose voice improved significantly. In this particular case a very high stability of airflow (demonstrated by a significant reduction of $\mathrm{CV}$ ) was achieved after treatment without a significant quantitative change in airflow.

\section{RESULTS}

The results reported in this study confirm the usefulness of aerodynamic evaluation of phonation in the diagnostic

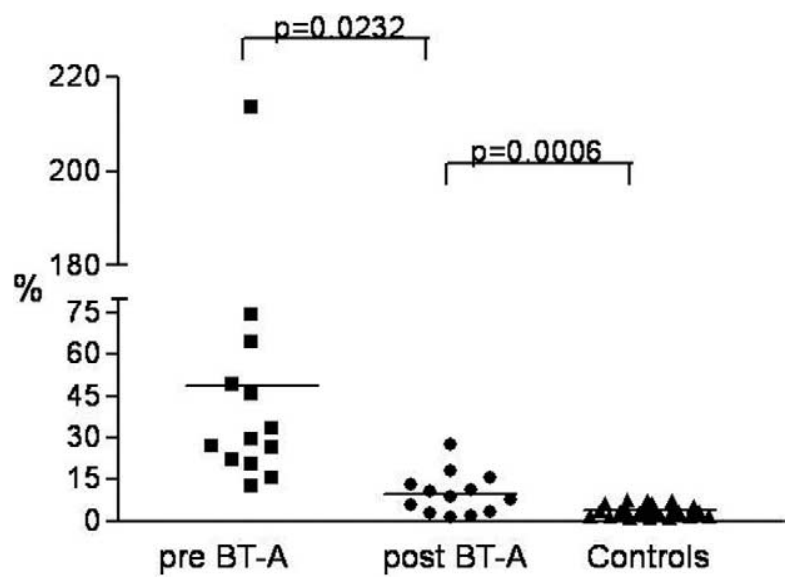

Figure 4 After BT treatment the coefficients of variation of oral airflow are significantly reduced, but they are still significantly higher than those of controls. 

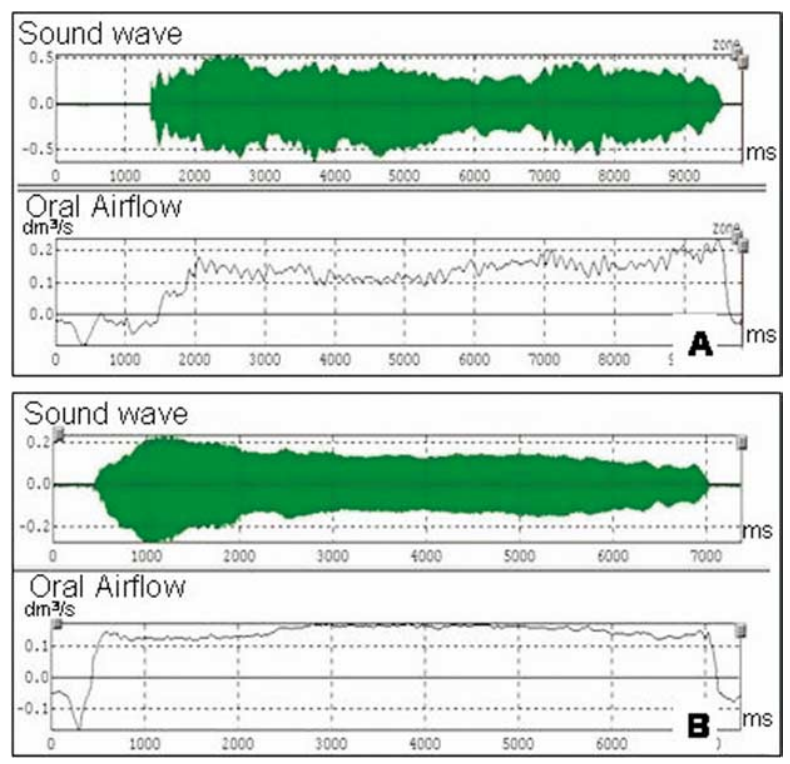

Figure 5 Tracings obtained before (A) and 18 days after (B) botulinum-A treatment in a 31-year-old female subject. The upper tracings are the sound waveforms whereas the lower tracings display the oral airflow (airflow) during the emission of a sustained vowel /a/. Waveforms and airflow tracings are both much more stable in the post-treatment recording. Despite similar airflow values $(167 \mathrm{cc} / \mathrm{sec}$ pre- and $164 \mathrm{cc} / \mathrm{sec}$ post-treatment), the airflow coefficient of variation has reduced from $12.71 \%$ to $2.06 \%$.

work-up and follow-up of subjects with $\mathrm{SD}$, a relatively rare disorder, undergoing treatment with $\mathrm{BT}$.

A few previous studies have measured oral airflow ${ }^{9-11}$ and its variability ${ }^{7,8,12}$ in SD subjects; the results were inconsistent. A low airflow in SD is an expected finding $^{9,10,12}$ considering the pathophysiology of the disease, because the over adduction of vocal folds during phonation may well hinder the normal flow of air through the glottis. Nevertheless some authors have reported mean airflow within normal limits. ${ }^{7,13}$ The subjects we studied, all of whom had adductor SD, had airflow values ranging from 24 to $671 \mathrm{cc} / \mathrm{sec}$, reflecting the heterogeneity of SD (Fig 1). Airflow values ranged widely also in the control group, confirming previous findings in normal subjects. ${ }^{14}$ Subjects had lower airflow values than healthy controls although the difference was not significant $(P=0.0928)$, probably owing to data dispersion.

Besides reflecting the widely ranging severity of disease, airflow may differ also owing to the various pathophysiological mechanisms. The several different types and subtypes of SD vary depending on the muscles involved by dystonic activity and also on other associated neurologic signs and symptoms. A recent study ${ }^{15}$ shows that all the intrinsic laryngeal muscles can be involved by dystonic activity in SD. Furthermore, the clinical presentation of adductor SD, the most common laryngeal dystonia, may differ if the disorder is associated with glottic tremor or if the subject uses compensatory mechanisms to avoid voice breaks. Some subjects with adductor SD adopt a whispered voice to overcome laryngeal spasms and to be able to communicate; this could explain why 2 subjects in our series had very high airflow values (383 and $671 \mathrm{cc} / \mathrm{sec}$ ). Unfortunately neither of these 2 subjects was available for a postinjection recording. Owing to its broad range of values, airflow therefore seems unreliable as a diagnostic test but may be useful for tracking functional changes during follow-up.

After BT treatment mean airflow increased in 10 of 13 subjects (of the 15 available post-treatment recordings), who experienced a subjective and perceptual voice improvement (Fig 3). The mean postinjection flow value was higher in subjects than in normal subjects, but the difference was not statistically significant.

Our results provide further evidence that the high CV of airflow in subjects with SD reflects the dystonic activity in the TA muscles during phonation. The subjects we studied had remarkably higher $\mathrm{CV}$ values than controls before treatment (Fig 2) and values decreased significantly after BT treatment (Fig 4). These results confirm previous findings by others, ${ }^{7,8,11}$ although our range is wider $(5.4 \%$ to $329.1 \%$ compared to $21.5 \%$ to $141 \%$, Davis et al, ${ }^{12}$ and $16.5 \%$ to $146.4 \%$, Finnegan et $\mathrm{al}^{7}$ ). The various series are difficult to compare also because they consider different voice samples. Whereas we used a sustained $/ \mathrm{a} /$, others ${ }^{7,8}$ analyzed the vowel /i/ in a syllable repetition task and on a shorter segment of voice production.

Although the absolute value of airflow will not discriminate subjects with SD from normal subjects, the CV of airflow allowed such a discrimination. Even after BT treatment most of our subjects still had significantly higher CV values than controls (Fig 4). Hence, even though the stability of the glottic vibrator improved, it did not return to normal.

In most subjects (12 of 13) in whom BT treatment improved phonation the reduced postinjection $\mathrm{CV}$ showed that airflow stability increased remarkably. Yet in 2 of 12 subjects airflow remained unchanged and in 1 of 12 it decreased. The tracings obtained in 1 of 3 subjects who had no increase in airflow after BT treatment (Fig 5) clearly show that despite having normal preinjection and postinjection airflow values $(167 \mathrm{cc} / \mathrm{sec}$ and $(164 \mathrm{cc} / \mathrm{sec})$, she had a markedly reduced CV (from $12.7 \%$ to $2.06 \%$ ). This subject achieved an excellent voice quality. Only one subject showed a marked reduction in airflow after treatment (see Results), although unexpectedly the CV also decreased remarkably. These findings seem to indicate that the higher steadiness of airflow is not entirely due to the flaccid paresis of the TA muscles obtained through BT peripheral action at the neuromuscular junction. Conversely, they imply that the improved stability of the laryngeal muscular system might arise from a central action of BT. Hence our findings could be in line with the conclusion of Finnegan et $\mathrm{al}^{7}$ that "increased stability of airflow could reflect [.. .] an increase in stability of the neural signal from the laryngeal motor neuron pool."

Although BT-A decreases muscle hyperactivity in dystonic muscles by preventing Ach release at the neuromuscular junction, some evidence suggests central nervous sys- 
tem (CNS) effects. ${ }^{7,16,17}$ When injected into a muscle, BT-A could affect the CNS either by a direct action, through retrograde axonal transport to the central structures, or indirectly, by altering the sensory inputs to the CNS, through a peripheral effect. ${ }^{16,17}$ An experimental study ${ }^{18}$ has shown that $\mathrm{BT}$ injected into the cat gastrocnemius muscle is transported to the spinal cord segments innervating the injected muscle. This study supports the hypothesis that BT may influence spinal cord circuitry through motor and intrafusal afferent axons. Furthermore, when injected into a muscle, BT causes denervation of both the intrafusal and extrafusal fibers. ${ }^{19}$ As a consequence, the spindle afferent input could be reduced or altered and ultimately this change might influence the central feedback mechanisms that modulate the activity of laryngeal muscles. Muscles spindles have been described in the intrinsic laryngeal muscles, ${ }^{20}$ and other mechanoreceptors in laryngeal joints. ${ }^{21}$ The sensory feedback deriving from muscles spindles and from the other mechanoreceptors probably influences the activity of the entire laryngeal motoneuron pool. This hypothesis receives support from clinical studies evaluating the effects of unilateral BT injection on the contralateral laryngeal muscles. ${ }^{10,16}$ After injecting BT-A into the TA muscle unilaterally, Bielamowicz and Ludlow ${ }^{16}$ found that electromyographic activity from both TA and cricothyroid muscles was reduced; they postulated that the achieved voice improvement could be due to both the well-known peripheral and to a central action of BT. Videoendoscopic observations by Zwirner et al ${ }^{10}$ showed that unilateral BT treatment reduced the dystonic contraction in laryngeal intrinsic muscles bilaterally.

\section{CONCLUSIONS}

In our study we treated TA muscles bilaterally. In three subjects stability of airflow persisted even when breathiness had subsided and airflow returned to a value similar or even lower than the preinjection one. Why it did so is unclear. SD is a complex disturbance of phonation that probably involves at the same time several laryngeal muscles, ${ }^{2}$ any of which may be predominant. ${ }^{15}$ In their study, Cannito and Johnson ${ }^{2}$ defined SD as a "continuum disorder" meaning that adductor and abductor spasms may both occur with different frequencies in the same subject. We hypothesize that BT injection into TA muscles might also modify the dystonic activity in other laryngeal muscles involved by spasms, either by diffusion or through an indirect effect, by reducing sensory inputs to the CNS.

As a further development of the study, serial recordings of airflow and $\mathrm{CV}$, between consecutive treatments, could be helpful to evaluate whether changes in the two variables are related. Our data confirm the validity of aerodynamic measures in studying the pathophysiology of spasmodic dysphonia and in monitoring voice changes after BT treatment. Studies of airflow stability may help to explain the possible effects of botulinum toxin on the CNS.

\section{REFERENCES}

1. Aronson AE, Brown JR, Litin EM, et al. Spastic dysphonia, II. Comparison with essential (voice) tremor and other neurologic dysphonias. J Speech Hearing Disord 1968;33:219-31. (Grade C).

2. Cannito MP, Johnson JP. Spastic dysphonia: a continuum disorder. J Commun Disord 1981;14:215-23. (Grade C).

3. Aronson AE. Clinical voice disorders. 2nd ed. New York: Thieme, 1985. (Grade D).

4. Blitzer A, Brin MF, Fahn S, et al. Clinical and laboratory characteristics of laryngeal dystonia: a study of 110 cases. Laryngoscope 1988; 98:636-40. (Grade C).

5. Pool KD, Freeman FJ, Finitzo T, et al. Heterogeneity in spasmodic dysphonia. Neurologic and voice findings. Arch Neurol 1991;48:305-9. (Grade C).

6. Blitzer A, Brin FB, Stewart CF. Botulinum toxin management of spasmodic dysphonia (laryngeal dystonia): a 12-year experience in more than 900 patients. Laryngoscope 1998;108:1435-41. (Grade C).

7. Finnegan E, Luschei E, Gordon J, et al. Increased stability of airflow following botulinum toxin injection. Laryngoscope 1999;109:1300-6. (Grade B).

8. Adams S, Durkin L, Irish J, et al. Effects of botulinum toxin type A injection on aerodynamic measures of spasmodic dysphonia. Laryngoscope 1996;106:296-300. (Grade B).

9. Woo P, Colton R, Casper J, et al. Analysis of spasmodic dysphonia by aerodynamic and laryngostroboscopic measurements. J Voice 1992;6: 344-51. (Grade C).

10. Zwirner P, Murry T, Swenson M, et al. Effects of botulinum toxin therapy in patients with adductor spasmodic dysphonia: acoustic, aerodynamic, and videoendoscopic findings. Laryngoscope 1992;102: 400-6. (Grade C).

11. Metha RP, Goldman SN, Orloff LA. Long-term therapy for spasmodic dysphonia: acoustic and aerodynamic outcomes. Arch Otolaryngol Head Neck Surg 2001;127:393-9. (Grade B).

12. Davis PJ, Boone DR, Carroll RL, et al. Adductor spastic dysphonia: heterogeneity of physiologic and phonatory characteristics. Ann Otol Rhinol Laryngol 1988;97:179-85. (Grade C).

13. Hirano M, Koike Y, von Leden H. Maximum phonation time and air usage during phonation. Folia Phoniatri (Basel) 1968;20:185-201. (Grade C).

14. Schutte HK. Aerodynamics of phonation. Acta Otorhinolaryngol Belg 1986;40:344-57. (Grade B).

15. Klotz DA, Maronian NC, Waugh PF, et al. Findings of multiple muscle involvement in a study of 214 patients with laryngeal dystonia using fine-wire electromyography. Ann Otol Rhinol Laryngol 2004; 113:602-12. (Grade C).

16. Bielamowicz S, Ludlow CL Effects of botulinum toxin on pathophysiology in spasmodic dysphonia. Ann Otol Rhinol Laryngol 2000;109: 194-203. (Grade C).

17. Currà $\mathrm{A}$, Trompetto $\mathrm{C}$, Abbruzzese $\mathrm{G}$, et al. Central effects of botulinum toxin type A: evidence and supposition. Mov Disord 2004; 19(Suppl):S60-4. (Grade D).

18. Wiegand H, Herman G, Woohoner HH. 125I-labelled botulinum A neurotoxin: pharmacokinetics in cats after intramuscular injection. Naunyn Schmiedebergs Arch Pharmacol 1976;292:161-5. (Grade C).

19. Rosales RL, Arimura K, Takenaga S, et al. Extrafusal and intrafusal muscle effects in experimental botulinum toxin-A injection. Muscle Nerve 1996;19:488-96. (Grade C).

20. Lucas Keene MF. Muscle spindles in the human laryngeal muscles. J Anat 1961;95:25-9. (Grade C).

21. Suzuki M, Kirchner JA. Sensory fibers in the recurrent laryngeal nerve. An electrophysiological study of some laryngeal afferent fibers in the recurrent laryngeal nerve of the cat. Ann Otol Rhinol Laryngol 1969;78:21-31. (Grade C). 